\title{
Coordinating Atypical Architectural Precast Concrete Façades
}

\section{Two categories}

\author{
Jeffrey Collins ${ }^{1}$, Russell Gentry ${ }^{2}$ \\ ${ }^{1}$ Kennesaw State University ${ }^{2}$ Georgia Institute of Technology \\ 1jcoll133@kennesaw.edu ${ }^{2}$ russell.gentry@design.gatech.edu
}

This research focuses on issues of coordination between designers and fabricators during early design. The aim of this work is to improve representations, enable more informed conversations, and streamline exchanges of digital models. In order to show the potential of the work, research is focused on architectural precast concrete facades. Previous work established methods for linking "global" and "local" parametric models of architectural intent and corresponding components, describing processes of mapping from individual custom panels to diagrammatic façade surfaces and vice-versa. Such mapping may be considered "direct," wherein individual panel boundaries - defined by surface patterning - allow simple mapping of data from global to local or from local to global descriptions. However, there are some buildings with architectural precast concrete façades which do not permit direct relationships between global and local descriptions. These atypical facades require "indirect" maps containing additional layers of information in order to coordinate global and local descriptions. This paper describes two categories of these indirect scenarios: "panelization" and "patterns across panels."

Keywords: BIM, Parametric modelling, Architectural precast concrete, Building facades

\section{INTRODUCTION}

The notion of linking building descriptions from designs and fabricators - among other project actors - is underpinned by the widespread belief that "the historical role of the designer as an author, a sole creator, is being replaced with semi-autonomous, algorithmically driven design workflows deeply embedded in a collective of digital communication infras- tructure." [Marble, 2012] In fact, the current disconnect of global and local descriptions extends beyond technical modes of working and depicting projects to conceptual meanings of drawings or models and cognition. Mitchell (1990) refers to these two approaches as "graphic primitives and abstract shape types" (building surface patterns) and "instantiated labeled objects" (individual panels). It can be further 
argued that the disconnect between building descriptions has been exaggerated by industry-focused software which align with goals for certain project actors; designer exploration and fabricator specification. Mapping between these descriptions can elucidate and associate global and local representations, not only of digital models but also within the minds of designers and fabricators; maps will serve as manifestations of "distributed cognition" for projects. [Hutchins, 2001] While this is true for other building descriptions - digital, technical, sketch, or otherwise - the use of digital models can unleash the capacity of computation to extend projects beyond those that can be traditionally represented while engaging form, materiality, and ways of making. [Shelden, 2014] Building façades are especially relevant to both architectural theory and practice as they are critical to a buildings' character but remarkably complex in assembly. The architectural precast façade offers, in particular, a system whose parts are discreet through surface panelization, customizable via extensive features, and fundamental to the overall buildings' aesthetic.

For some time, design teams have been organizing their processes so that the transfer of design proposals occurs via digital model and online. Others, especially on the construction and fabrication side of the industry, have not been as quick to accept these approaches; learning new software and workflows, and defining and customizing digital models requires a significant amount of time. In the end, however, since Owners are more frequently requiring digital modelling and BIM processes and documents as part of their design and construction contracts, each fabricator must develop digital models of the architectural components that they provide. Design intent for the overall building façades must be discretized into individual pieces and translated - applying expert knowledge regarding panel features, form construction, transportation and assembly limitations, and more - into directives for fabrication. Previous work documented the process and possibilities of incorporating digital modelling into an existing architectural precast concrete fabricator workflow. [Collins, 2016] This work demonstrated that, while parametric digital models do help to achieve precise geometry and collection of various sorts of data for fabrication and construction activities, coordination and conversation among various actors is still critical to achieving desired design outcomes.

While research aims to include a wide variety of precast possibilities, architectural precast concrete façade panels included in this work assume:

- Pieces are custom-designed and unique to a particular building

- Pieces are cast by pouring wet concrete into
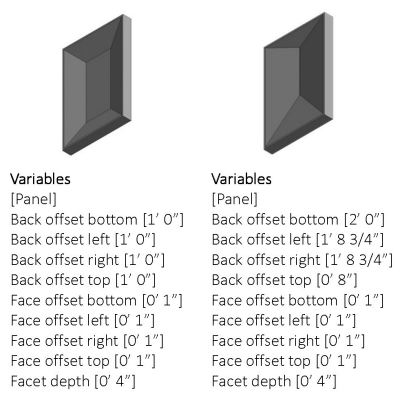

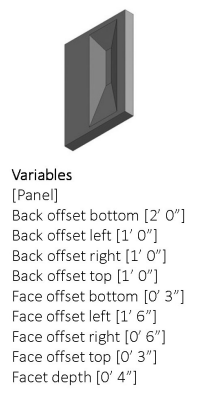

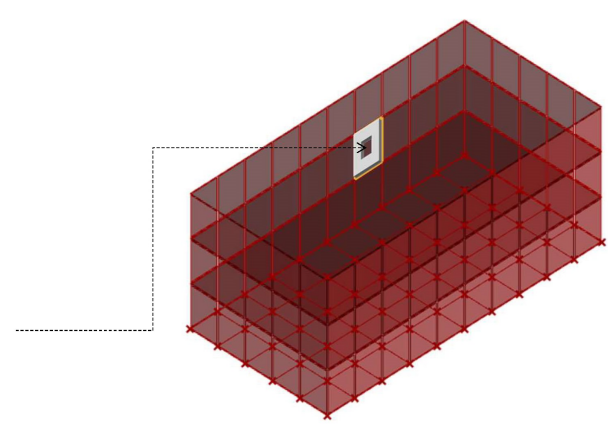

Figure 1

Example panels and variables and application to façade pattern from Collins and Gentry (2019) 
forms

- Pieces are cast at a location other than the final position on the building and, after curing are then transported to the site for installation

- Pieces are designed as an integral part of the building exterior wall

The above constraints exclude some concrete work; cast-in-place concrete, cement board products, and pieces used in applications other than walls, to name a few. However, this scope intentionally does not limit precast in terms of material make-up or production method.

\section{FAÇADES AND PANELS}

In this research, the terms façade, envelope, and skin are used interchangeably to refer to the exterior surface of a building. It is worthwhile to note the multiple meanings of these words and the potential architectural implications. A "façade" refers to a "face." "Envelope" and "skin" are each both verbs and nouns; enclosing structures and a series of actions leading to their production. A detailed section cut through a building façade reveals that the architectural implication of envelopes/skins are in fact not paper-thin membranes, but are often thick systems of layers that make up the assembly of exterior walls and separate the interior from the exterior. Façades therefore create interior environments; critical to overall building performance. [Hegemann, 1929; Banham, 1969] Trubiano (2013) discusses the "spatialization" of building skins which "not only...advance the energy performance of the buildings they enclose, they also represent a new way of thinking about envelope for those desirous of surface depth and substance."

Dutton Architects (2013) provides a review of the history and insinuations of the pervasive focus on façade design, stressing two important points for consideration. The first point emphasizes the use of the word façade as the "face" of the building "prior to modernism... this face was a separately designed architectural feature... [which] together with the façades of other buildings, created the identity of the street and public spaces." Whereas "mod- ernism... focused on 'elevations'... exteriors were seen as the result of internal forces of spatial design and programmatic needs." The second point suggests that many of the building parameters such as size are often predicated by zoning, site, parking, and other client requirements leaving only the façade - a "sliver of fetishized architectural space" - left to design. Menzel (2012) has organized a collection of contemporary façade designs, demonstrating the trend to focus on performance, material, and unconventional patterning.

From the aspect of construction, Turgut (2007) describes six types of wall cladding systems:

- Stick Systems

- Unit Systems

- Unit and Mullion Systems

- Panel Systems

- Column Cover and Spandrel Systems

- Structural Glazing Systems

Architectural precast concrete façades fall within the category of "panel systems." Panel systems are characterized by large sized units attached to the buildings' superstructure with clips and/or anchors. Efficiency is obtained through standardization of panels across façades. This pattern that defines the bounds of individual pieces of precast is called panelization. The majority of precast (and other panel system) façades consist of either flat surfaces, but they may also be "ruled surfaces" or "developable surfaces." Patterns consist, for the most part, of triangular or quadrilateral panels. Each of these factors has an effect on manufacturing. This research aims to extend previous work on panelization [Pottman et al, 2007; Pottman et al, 2015] by formalizing knowledge for precast façades and establishing a workflow for coordinating digital models among project actors.

\section{METHODS}

Documentation and models of existing precedent buildings with architectural precast concrete facades has developed a process for creating parametric maps (depicted in Figure 1) in order to assess the ef- 


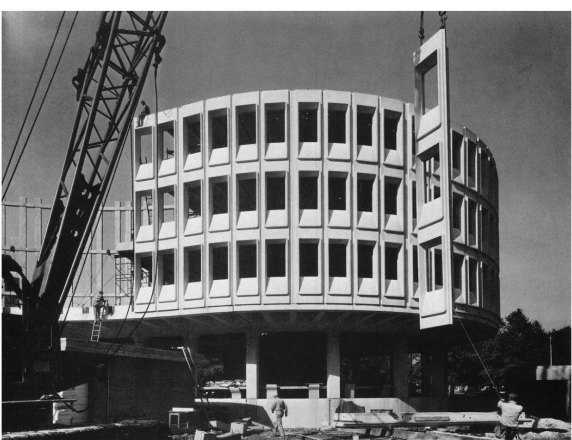

a

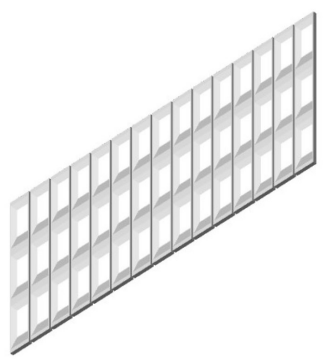

fect on design outcomes. [Collins, 2019] Christenson (2009) has accomplished similar work, parametrically modelling and flexing existing precedent buildings, concluding that "the use of parametric modelling in the study of existing architecture constitutes an opportunity to reveal possible semantic relationships within a subject work of architecture." The models are used to demonstrate the process of developing parametric maps, both as a means of engaging issues of fabrication in early stages of design as well as to demonstrate benefits of incorporating such maps in future state workflows. Hollan et al (2000) define similar research methods as "cognitive ethnography," aimed at discovering "not only... what people know, but... how they go about using what they know to do what they do." Two main categories for mapping precast are defined: direct and indirect.

In "direct" mapping, individual panel boundaries

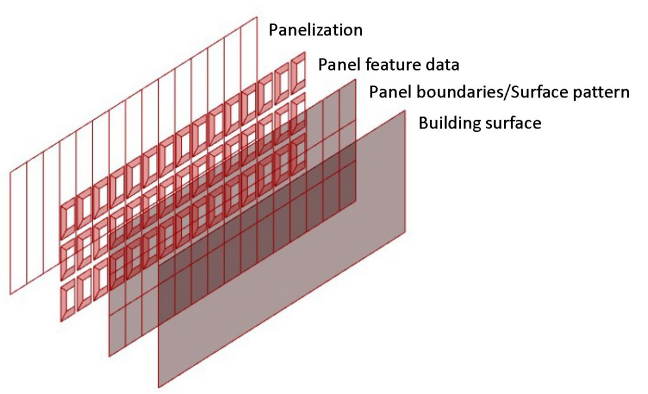

Figure 2

Roundhouse construction photo

(a), layers of panelization (b), composite panelization model (c), and mapped panels and mass model (d) $\mathrm{b}$

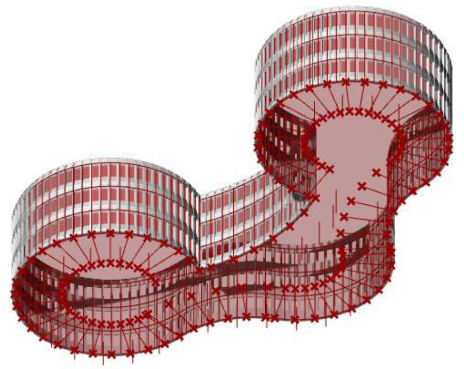

d

- defined by a combination of scaffold models, regions, and surface patterns - allow simple translation of data from global to local or from local to global descriptions. That is, each individual panel boundary defines a single piece of architectural precast concrete and all associated geometrical features. [Collins and Gentry, 2019] It should be noted that the term "direct" is used conceptually here, denoting the relationship between panel boundary and panel. Direct exchanges of model data as described in Eastman et al (2009) uses the term literally, transferring data between actors; this continues to also be a goal of the research.

Unlike the buildings and models described above, there are some architectural precast concrete façades which do not permit direct relationships, or simple translation, between global and local descriptions. Such "indirect" maps require additional lay- 
Figure 3

150 Rouse

Boulevard photo (a), and layers of patterns across panels (b)

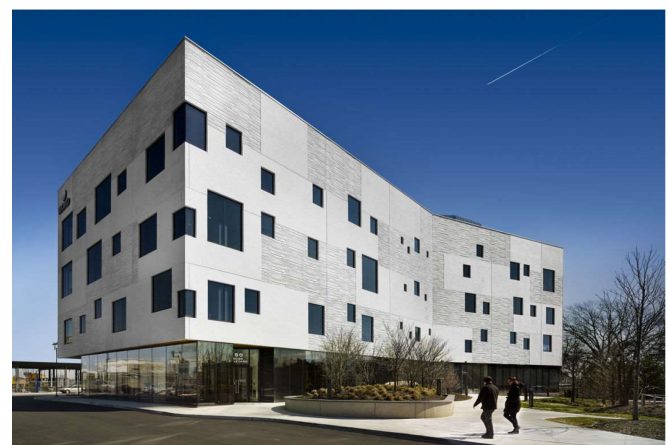

a

ers of information in order to coordinate global and local descriptions. Two such indirect scenarios are described in this paper: panelization and patterns across panels. It should be noted here as well that the term "indirect" is used conceptually, denoting a nonlinear relationship between façade features and panels. It is still the goal of this research to allow direct exchanges of model data between actors, even or perhaps especially - for relationships that are indirect.

\section{PANELIZATION}

Patterns perceived on building façades do not necessarily dictate joints between individual precast pieces. Precasters, balancing many fabrication and assembly issues, often prefer larger panels than those that might be suggested in design descriptions. This could result in "joining" adjacent panel boundaries together. In such cases, architectural features that may have been defined as joints between panels in design intent documents become reveals or, when panels merge, the joint could be erased. Conceptually, this requires managing additional layers to control both surface patterns and panelization patterns.

Philadelphia Police Department Headquarters (Roundhouse) by Geddes, Brecher, Qualls and Cunningham in Figure $2 \mathrm{a}$ demonstrates panelization. If one were to create a digital model representation

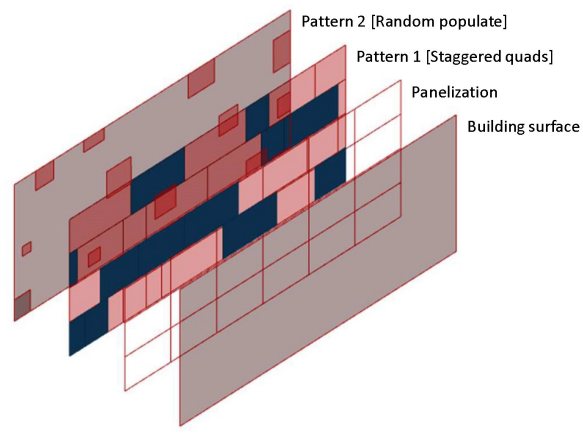

b

of the surface pattern for the building in the background of the construction photo, it most likely would describe three panel boundaries vertically one for each level of the building. However, we can see from the panel being lifted into place in the foreground that the panels were actually fabricated as three-story tall pieces. [Hahn, 2016] Layers of data required for coordination of panelization are diagrammed in Figure $2 \mathrm{~b}$. First, the panel boundaries/surface pattern defines the design intent. Next, data regarding panel features is extracted from customized individual panels. Then, a distinct panelization pattern is applied. Each of these layers is projected back to the building surface; illustrated on a flat surface in Figure $2 c$ and on the curvaceous building mass in Figure 2d.

\section{PATTERNS ACROSS PANELS}

There are some building façades where a pattern, texture, relief, or similar "gesture" may cross over two or more panels. These buildings' surface patterns may be indifferent to panelization, expressing distinct layers of composition. Again, this requires managing additional layers to control both surface features and joints between panels.

150 Rouse Boulevard by Digsau (Figure 3a) is an interesting example because there are clearly multiple layers of patterns occurring and controlling var- 


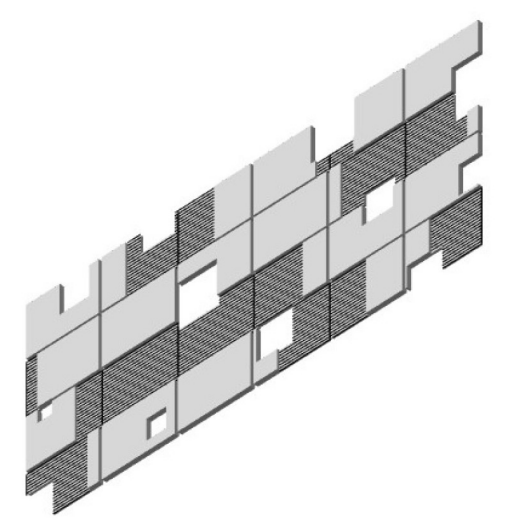

a

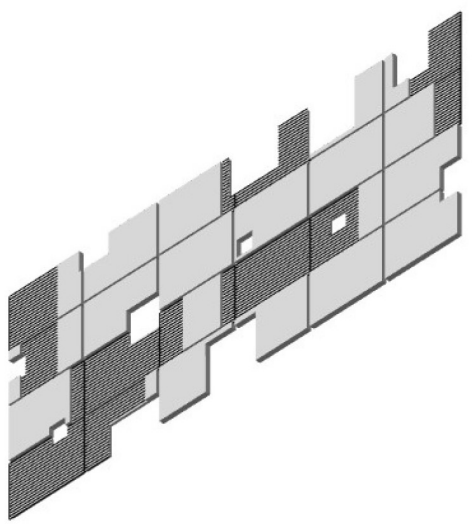

C

ious characteristics of the façade; the architect describes these as "multiple textures [to] create a largescale pattern overlaid over the pattern formed by the construction joints of the panels." [Digsau, 2018] These layers are diagrammed in Figure 3b. Unlike Roundhouse, the panelization pattern is clear for 150 Rouse Boulevard. However, there are two additional layers of features that violate the panel boundaries. First, a staggered quad pattern describes textured re-

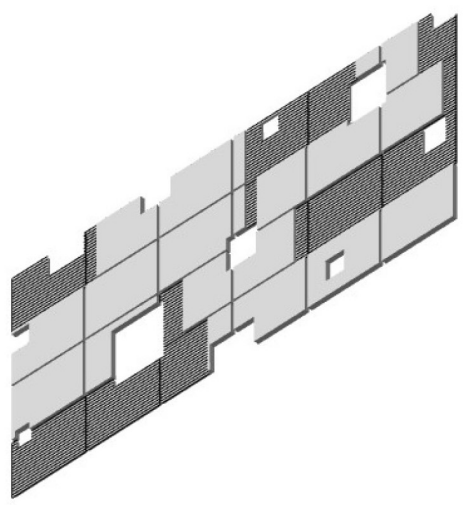

Figure 4

150 Rouse

Boulevard patterns across panels variations b

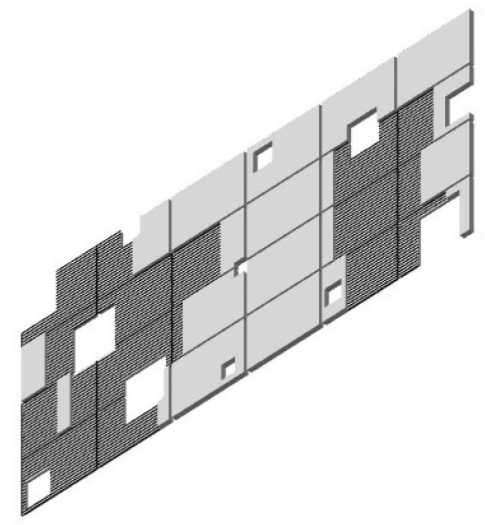

d

lief areas. Then, openings are randomly populated across the surface. Again, all of this layered geometry is described and projected back to the building surface. Variations are illustrated, wherein openings and relief areas are varied while panelization remains constant; samples are shown in Figure 4. Clearly, an enormous amount of designs are possible. 


\section{SUMMARY}

Research has documented, modelled, and referenced precedent buildings with architectural precast concrete façades in order to demonstrate the process of developing various parametric maps and their effect on the design outcomes of those buildings. It is the intent, however, for this work to allow new opportunities for precast buildings beyond those described. This paper has described two approaches for coordinating digital models of architectural precast concrete façades and panels which display indirect mapping between global and local descriptions. It is not proposed that a given project uses one of these types exclusively, or that this is an exhaustive list of indirect mapping types. Rather, a variety of mapping methods could be used iteratively during the design process to coordinate among various scaffold and panel models and between project actors. Alternate map types for future work may include special considerations for GFRC panels, maps limiting sizes of panels based on weight or other measures, incorporation of reinforcing bars, insulation, mechanical or other building systems, modelling of complex formwork construction, and more. Furthermore, mapping strategies could be executed in an even broader sense, before material selection. This research has focused on architectural precast concrete façades in order to show the potential of the proposed framework. However, parametric digital models could be similarly used to explore a variety or combination of different materials. Extensions could also track the effect of such design decisions and material specification on project costs.

\section{ACKNOWLEDGMENTS}

This paper is part of the doctoral dissertation by the first author from Georgia Institute of Technology. The authors acknowledge the financial support of Autodesk and Digital Building Laboratory. Any opinions, findings, and conclusions or recommendations expressed in this material are those of the authors and do not necessarily reflect the views of the funding agencies.

\section{PHOTO CREDITS}

Figure 2a: Image from Pyburn (2015)

Figure 3a: Image from DIGSAU (2018)

\section{REFERENCES}

Dutton Architects, Accessed September 192018 'Seeing Through the Façade', Grids Blog, http://www.gridsblog.com/wordpress/seeing-through-the-facadel

Banham, R 1969, The Architecture of the Well-Tempered Environment, The University of Chicago Press

Christenson, M 2009, 'Testing the Relevance of Parameterization to Architectural Epistemology', Architectural Science Review, 52.2, pp. 135-141

Collins, J 2016 'Incorporating BIM into Architectural Precast Concrete Fabrication', 33rd International Symposium on Automation and Robotics in Construction, IS$A R C$

Collins, J 2019, A Framework for Coordinated Models of Architectural Precast Concrete Façades, Ph.D. Thesis, Georgia Institute of Technology

Collins, J and Gentry, R 2019 'Mapping Precast: Linking Global and Local Descriptions of Architectural Precast Concrete', 2019 ASCE International Conference on Computing in Civil Engineering (i3CE2019)

DIGSAU, Accessed August 32018 '150 ROUSE BOULEVARD', http://www.digsau.com/projects/150-rouse

Eastman, C, Sacks, R, Panushev, I, Aram, S and Yagmur, E 2009, The National Building Information Modeling Standards: Information Delivery Manual for Precast Concrete, The Charles Pankow Foundation and Precast Concrete Institute

Hahn, A May 62016 'Building Stories: The Roundhouse', PlanPhilly, http://planphilly.com/eyesonthestreet/2016/05/06/build the-roundhouse

Hegemann, W 1929, Facades of Buildings, Ernest Benn Limited

Hollan, J, Hutchins, E and Kirsh, D 2000, 'Distributed cognition: toward a new foundation for humancomputer interaction research', ACM Transactions on Computer-Human Interaction (TOCHI), 7(2), pp. 174196

Hutchins, E 2001, 'Distributed cognition', in Wright, J (eds) 2001, International Encyclopedia of the Social and Behavioral Sciences, Elsevier, p. 2068-2072

Marble, S 2012, 'Digital Workflows in Architecture: Design, Assembly, Industry', in Marble, S (eds) 2012, Digital Workflows in Architecture: Design, Assembly, Industry, Birkhauser

Menzel, L 2012, Facades: Design, Construction \& Technol- 
ogy, Braun Publishing AG

Mitchell, W 1990, The Logic of Architecture, The MIT Press

Pottman, H, Asperl, A, Hofer, M and Kilian, A 2007, Architectural Geometry, Bentley Institute Press

Pottman, H, Eigensatz, M, Vaxman, A and Wallner, J 2015 , 'Architectural geometry', Computers \& Graphics, 47, pp. 145-164

Pyburn, J 2015 'Presentation for the DOCOMOMO National Symposium', International Committee for Documentation and Conservation of Buildings, Sites and Neighbourhoods of the Modern Movement

Shelden, D 2014, 'Information, Complexity and the Detail', in Garcia, M (eds) 2014, Architectural Design: Future Details of Architecture, Academy Press

Trubiano, F 2013, 'Performance Based Envelopes: A Theory of Spatialized Skins and the Emergence of a New Professional', Buildings 2013, 3, pp. 698-712

Turgut, D 2007, The evolution and change of building facades: A research for developing alternative composite surface materials, Master's Thesis, Izmir Institute of Technology 